\title{
Safety and Feasibility of Novel Reconstruction Method Using Long and Narrow Cobra- Head- Shaped Gastric Tube in Laparoscopic Proximal Gastrectomy for Cancer
}

\section{Yoshitake Ueda}

Department of Comprehensive Surgery for Community Medicine, Oita University Faculty of Medicine Takahide Kawasaki

Department of Comprehensive Surgery for Community Medicine, Oita University Faculty of Medicine Sanshi Tanabe

Department of Gastroenterological and Pediatric Surgery, Oita University Faculty of Medicine Kosuke Suzuki

Department of Gastroenterological and Pediatric Surgery, Oita University Faculty of Medicine Shigeo Ninomiya

Department of Gastroenterological and Pediatric Surgery, Oita University Faculty of Medicine Hidefumi Shiroshita

Department of Gastroenterological and Pediatric Surgery, Oita University Faculty of Medicine

\section{Tsuyoshi Etoh}

Department of Gastroenterological and Pediatric Surgery, Oita University Faculty of Medicine

\section{Masafumi Inomata}

Department of Gastroenterological and Pediatric Surgery, Oita University Faculty of Medicine

Norio Shiraishi ( $\nabla$ norioh@oita-u.ac.jp )

Department of Comprehensive Surgery for Community Medicine, Oita University Faculty of Medicine

\section{Research Article}

Keywords: Laparoscopic gastrectomy, Proximal gastrectomy, Esophagogastrostomy

Posted Date: October 29th, 2021

DOI: https://doi.org/10.21203/rs.3.rs-1003160/v1

License: (1) This work is licensed under a Creative Commons Attribution 4.0 International License. Read Full License 


\section{Abstract}

Background. To clarify the safety and feasibility of laparoscopic proximal gastrectomy (LPG) with our novel reconstruction methods, clinical outcomes of this LPG were evaluated and compared to those of LPG with our conventional method.

Methods. Novel method is a reconstruction with a long and narrow gastric tube with widening of the proximal side of the gastric tube created by linear stapler. Esophagogastrostomy is performed by direct anastomosis with overlap method between the posterior wall of the esophagus and anterior wall of the gastric tube using a linear stapler. In conventional method, direct anastomosis between the esophagus and a gastric tube by a circular stapler was performed. Short- and long-term outcomes of a novel method were compared with those of conventional method.

Results. A total of 39 patients whom LPG was performed were enrolled in this retrospective study. The amount of blood loss in the Novel method group $(n=30)$ was significantly less than those in the Conventional method group ( $n=9)$ (40 vs. $110 \mathrm{ml}, \mathrm{p}<0.01$ ). No cases of anastomotic leakage and stenosis were observed in both groups. The cases of postoperative reflux esophagitis at 1 year after operation in the Novel group were less than those in the Conventional group (10\% vs. $33 \%)$. In the Novel group, postoperative recurrence was observed in 2 patients (7\%).

Conclusions. LPG with novel reconstruction method using long and narrow cobra- head-shaped gastric tube can be easily performed, and may be feasible for the treatment of gastric cancer in the upper third of the stomach.

\section{Background}

In Japan and other Asian countries, the frequency of early gastric cancer (EGC) in the upper third of the stomach continues to increase along with advances in diagnostic techniques, mass screening programs, and removal of helicobacter pylori $[1,2]$. Although total gastrectomy $(T G)$ is more often performed for proximal ECG in Western countries, not only TG but also PG is carried out in Japan. Since Uyama et al. have firstly reported laparoscopic proximal gastrectomy (LPG) in 1995 [3], the frequency of LPG is increasing year by year in Japan. Surprisingly, according to the 14th nationwide survey of endoscopic surgery in Japan by the Japan Society of Endoscopic Surgery, LPG for gastric cancer has been performed in approximately 4700 cases during the 10-year period from 2008 to 2017, which has increased approximately 6 times compared with the past 10 years [4]. The reason for the increased number of LPG is that the benefits of PG over TG include the prevention of postoperative weight loss and undernutrition by preserving the gastric function $[5,6]$. Therefore, LPG is classified as an optional treatment for proximal EGC in Japanese gastric cancer treatment guidelines [7].

Although PG is theoretically superior procedure for upper one-third of EGC over TG, PG is not the standard procedure worldwide. As problems of $\mathrm{PG}$, the high frequency of anastomosis-related complications such as anastomotic leakage and stenosis, and reflux symptom are reported [8-10]. Especially, the high 
incidence of reflux esophagitis after PG is the fateful problem that is hard to be solved, because of the removal of anti-reflux mechanism including His angle and the lower oesophageal sphincter by PG. To improve these problems, a variety of reconstructive techniques following a PG have been developed to date [11-15]. However, the reconstructive method of PG has not been standardized yet. We devised the reconstruction method using the narrow gastric tube in open PG in 1999 [16]. And, we have applied this method (conventional method) to the laparoscopic surgery in 2006. For more decreased incidence of anastomosis-related complications, we have improved the esophagogastric reconstruction by using long and narrow cobra head-shaped gastric tube (novel method) in 2009 [17].

This study aimed to clarify the safety and feasibility of LPG with the novel method in the comparison with those of LPG with our conventional method from the viewpoint of short-and long-term outcomes.

\section{Patients And Methods}

\section{Patients}

From April 2006 to February 2019, a total of 39 patients whom LPG was performed at Oita University Hospital were enrolled in this study. Nine patients underwent LPG with conventional method between April 2006 and March 2009 (Conventional group). And, 30 patients underwent LPG with novel method between April 2009 and February 2019 (Novel group). Diagnosis of all patients was made according to preoperative endoscopy, endoscopic ultrasonography, upper gastrointestinal series, and abdominal computed tomography (CT). The staging of the tumor was classified according to the Japanese Classification of Gastric Carcinoma by the Japanese Gastric Cancer Association, 3rd English edition [7]. Our indication for this LPG is proximal gastric cancer, for which the preoperative diagnosis is clinical T1NOMO or clinical T2NOMO gastric cancer located in the upper one-third of the stomach without esophageal invasion, and it was considered that at least two-thirds of the stomach could be preserved preoperatively in all cases. Differentiated types included papillary and tubular adenocarcinomas, and undifferentiated types included poorly differentiated adenocarcinoma, signet ring cell carcinoma, and mucinous adenocarcinoma. All tissues were examined by expert pathologists.

\section{Surgical Procedure of LPG with long and narrow gastric tube reconstruction: novel method}

LPG with D1+ lymph nodes dissection (nodes no. 1, 2, 3, 4sa, 4sb, 7, 8a and 9) were performed according to the Japanese gastric cancer treatment guidelines 2018 (5th edition) [7]. During the laparoscopic procedure, the upper part of the stomach is fully mobilized with perigastric and suprapancreatic lymph nodes dissection. The vagus nerves, especially, the hepatic and the peripheral pyloric branches, are always preserved. And then the abdominal esophagus is transected. After a mini-laparotomy is created, the entire stomach is pulled outside. A long and narrow gastric tube (more than $20 \mathrm{~cm}$ in length, $3 \mathrm{~cm}$ width) with widening of the proximal side (6cm in length) of the gastric tube like a cobra's head is created using by linear stapler (Figure 1,2). A cobra's head gastric tube is made for formation of the pseudo- 
fundus. A pyloroplasty is not always performed. After the pneumoperitoneum is recreated, esophagogastrostomy is performed by direct anastomosis with overlap method between the posterior wall of the esophagus and anterior wall of the gastric tube using a 45-mm linear stapler under laparoscopic view (Figure 3). The entry hole for anastomotic stapler is closed with a continuous suture by a synthetic absorptive thread with a barb. To prevent esophageal reflux, both the right and left ends of the esophageal wall are fixed to the gastric wall with laparoscopic interrupted sutures (Figure 4). And, we always perform the suture fixation between bilateral crus of diaphragm and esophagus wall for preventing the torsion of the gastric tube (Figure 5,6 ).

\section{Surgical Procedure of LPG with gastric tube reconstruction: conventional method}

As for all cases in LPG with conventional method, direct anastomosis between the esophagus and gastric tube by a circular stapler was performed. After the upper part of the stomach was fully mobilized, the abdominal esophagus was transected. The stomach was cut between the points of the distal three fourths of the lesser curvature and a half of the greater curvature, and a long gastric tube measuring 15 $\mathrm{cm}$ in length and $4 \mathrm{~cm}$ in width was made. The lower esophagus is anastomosed to the posterior wall of the gastric tube with a circular stapler inserted through a small opening made on the anterior wall of the stomach. Direct anastomosis between the esophagus and gastric tube was completed.

\section{Evaluation of short- and long-term outcomes}

Short- and long-term outcomes of 30 patients who underwent LPG with novel method were compared with those of 9 patients who underwent LPG with conventional method. We examined the following clinicopathological characteristics of all patients undergoing LPG, such as age, sex, body mass index (BMI), clinicopathological findings including tumor size, clinical TNM factors, pathological TNM factors. Surgical findings, such as operation time and blood loss, were also examined. We also examined the following data to evaluate the short- and long-term outcomes, such as postoperative mortality, start of diet food, postoperative hospital stay, postoperative complications defined as any condition requiring conservative or surgical treatment occurring within 30 days after the operation, including anastomotic leakage, anastomotic stenosis, pancreatic fistula, stasis, and postoperative general complications including respiratory, cardiovascular, and renal disorders, and enterocolitis. Postoperative complications were classified according to the Clavien-Dindo (CD) classification [18]. Patients were routinely followedup by clinical visits every 6 months for 5 years at least. They consisted of a clinical examination, blood tests, thoraco-abdominal CT examination. Followed-up endoscopy was routinely performed at 1 year after operation to evaluate reflux esophagitis, classified according to the Los Angeles classification [19].

\section{Statistical analysis}

Quantitative data are given as the median and range. These analyses were carried out using SPSS ver. 24 (SPSS Inc., Chicago, IL, USA).

Ethical considerations 
This was a retrospective study using surgical and clinicopathological records and follow-up data, approved by the Institutional Review Board of Oita University Hospital, Oita, Japan (Approval No. 542). The study was conducted in accordance to Helsinki declarations, Ethiopian National Research Ethics Guidelines, and Institutional regulations on research ethics. All participants of the study provided signed written informed consent before initiation of the data collection.

\section{Results}

The patients' demographics are presented in Table 1. All patients in the Conventional group had EGC. Whereas 7 patients had clinical T2 tumor in Novel group. Final pathological diagnosis showed p-stage I in all patients in Conventional group. On the other hand, in Novel group, 2 patients had p-stage II tumor and 1 patient had p-stage III tumor. The surgical and short-term outcomes of all patients are shown in Table 2. In the operation time, there were no significant differences between the two groups (Novel vs. Conventional: 299 vs. $269 \mathrm{~min}$ ). The amount of blood loss in the Novel group was significantly lower than those in the Conventional group ( $40 \mathrm{vs} .110 \mathrm{ml}, \mathrm{p}<0.01$ ). The number of harvested lymph nodes in the Novel group were significantly more than those in the Conventional group (18 vs. $12, p<0.01)$. No cases of conversion to open surgery and intraoperative death were observed in both groups, and 1 case of intraoperative complication (blood transfusion due to intraoperative bleeding) was observed in the Conventional group. Radical operation was performed in all patients of both groups. In the Novel group, postoperative complications were observed in 3 patients $(10 \%$, pancreatic fistula, pneumonia, and stasis in each 1 patient). No cases of anastomotic leakage and stenosis were observed in both groups. There were no significant differences in start of diet and postoperative hospital stay between two groups. 
Table 1

Patients' demographics

\begin{tabular}{|c|c|c|c|}
\hline Variables & $\begin{array}{l}\text { Novel group } \\
(n=30)\end{array}$ & $\begin{array}{l}\text { Conventional group } \\
(n=9)\end{array}$ & p \\
\hline Age (years, mean $\pm S D$ ) & $70 \pm 9$ & $63 \pm 10$ & NS \\
\hline \multicolumn{4}{|l|}{ Gender } \\
\hline Male & 23 & 5 & NS \\
\hline Female & 7 & 4 & \\
\hline 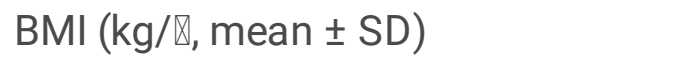 & $22.3 \pm 3$ & $23.4 \pm 3$ & NS \\
\hline Previous treatment with ESD & $12(40 \%)$ & $2(22 \%)$ & NS \\
\hline \multicolumn{4}{|l|}{ Clinical diagnosis } \\
\hline Clinical T stage (T1a / T1b / T2) & $9 / 14 / 7$ & $5 / 4 / 0$ & $\begin{array}{l}\text { NS } \\
(p=0.07)\end{array}$ \\
\hline Clinical N stage (N0 / N1) & $27 / 3$ & $9 / 0$ & NS \\
\hline Clinical stage (IA / IB / II) & $22 / 5 / 3$ & $9 / 0 / 0$ & $\begin{array}{l}\text { NS } \\
(p=0.09)\end{array}$ \\
\hline Tumor size (mm, mean $\pm S D)$ & $24 \pm 13$ & $31 \pm 14$ & NS \\
\hline \multicolumn{4}{|l|}{ Pathological diagnosis } \\
\hline \multicolumn{4}{|l|}{ Histological type } \\
\hline Differentiated / Undifferentiated & $25 / 5$ & $6 / 3$ & NS \\
\hline $\begin{array}{l}\text { Pathological T stage (T1 / T2 / T3 / } \\
\text { T4) }\end{array}$ & $23 / 4 / 2 / 1$ & $7 / 2$ / 0 / 0 & NS \\
\hline Pathological N stage (N0 / N1 / N2) & $27 / 2 / 1$ & $8 / 1 / 0$ & NS \\
\hline Pathological stage (IA / IB / II / III) & $22 / 5 / 2 / 1$ & $7 / 2 / 0 / 0$ & NS \\
\hline
\end{tabular}


Table 2

Surgical and short-term outcomes of patients undergoing LPG

\begin{tabular}{|c|c|c|c|}
\hline Variables & $\begin{array}{l}\text { Novel group } \\
(n=30)\end{array}$ & $\begin{array}{l}\text { Conventional group } \\
(n=9)\end{array}$ & p \\
\hline $\begin{array}{l}\text { Operation time } \\
(\text { min, mean } \pm S D)\end{array}$ & $299 \pm 55$ & $269 \pm 58$ & NS \\
\hline Blood loss (ml, median) (range) & $40(3-220)$ & $110(5-3210)$ & $p<0.01$ \\
\hline Harvested lymph nodes (mean \pm SD) & $18 \pm 9$ & $12 \pm 4$ & $p<0.01$ \\
\hline Coversion to open surgery & 0 & 0 & \\
\hline Intraoperative complication & 0 & 1 (blood transfusion) & NS \\
\hline R0 resection & $30(100 \%)$ & $9(100 \%)$ & NS \\
\hline Mortality & 0 & 0 & \\
\hline Postoperative complications & $3(10 \%)$ & $1(11 \%)$ & NS \\
\hline Anastomotic leakage & 0 & 0 & \\
\hline Anastomotic stenosis & 0 & 0 & \\
\hline Pancreatic fistula & $1(3 \%)$ & 0 & \\
\hline Pneumoniae & $1(3 \%)$ & $1(11 \%)$ & \\
\hline Stasis & $1(3 \%)$ & 0 & \\
\hline Start of diet (days, mean \pm SD) & $5 \pm 2$ & $5 \pm 1$ & NS \\
\hline $\begin{array}{l}\text { Postoperative hospital stay (days, mean } \\
\pm \text { SD) }\end{array}$ & $19 \pm 11$ & $15 \pm 3$ & $\begin{array}{l}\text { NS } \\
(p=0.07)\end{array}$ \\
\hline
\end{tabular}

The data of long-term outcomes are summarized in Table 3. All patients received a postoperative endoscopy at 1 year after operation. Reflux esophagitis of grade $\mathrm{C}$ of the Los Angeles classification was observed in each 3 patients in both groups (10\% vs. $33 \%)$. The cases of postoperative reflux esophagitis in the Novel group were less than those in the Conventional group, but not significantly. All of these patients were well-controlled by medication of proton-pump inhibitor only. During the median follow-up of 1270 (range 13-3868) days, postoperative recurrence was observed in 2 patients with advanced proximal gastric cancer (stage IIB and Stage IIIC) $(7 \%)$ in the Novel group. No postoperative recurrence was observed in the Conventional group. 
Table 3

Long-term outcomes of patients undergoing LPG

\begin{tabular}{llll} 
Variables & $\begin{array}{l}\text { Novel group } \\
(\mathbf{n}=30)\end{array}$ & $\begin{array}{l}\text { Conventional } \\
\text { group } \\
(\mathbf{n}=9)\end{array}$ & p \\
$\begin{array}{l}\text { Postoperative endoscopic findings at 1 year after } \\
\text { operation }\end{array}$ & 0 & 0 \\
\hline Stenosis & $3(10 \%)$ & $3(33 \%)$ \\
$\begin{array}{l}\text { Reflux esophagitis } \\
\text { LA grade C) }\end{array}$ & $2(7 \%)$ & 0 \\
\hline Recurrence & & NS \\
\hline LA: Los Angeles, NS: not significant & & NS \\
\hline
\end{tabular}

\section{Discussion}

In this study, we compared the clinical outcomes between our novel method and conventional method following LPG. All patients in this study were completed in curative resection by LPG. In comparison between the Novel and Conventional group, the Novel group tended to have more advanced cancer patients. There were no differences in the operation time and the incidence of postoperative complications between the two groups, whereas the amount of blood loss in the Novel group was less than those in the conventional group. Postoperative anastomosis-related complications such as leakage and stenosis did not occur in this study. Although there was no significant difference, the frequency of postoperative reflux esophagitis in the Novel group was lower than those in the Conventional group. The LPG with our novel reconstruction method for proximal EGC is a simple, safe technique that may prevent anastomosis-related complications, especially esophageal reflux.

Regarding the surgical treatment for EGC in the upper third of the stomach, the following three issues have been mainly discussed; the first issue is the operation method, TG or PG. The second is the reconstruction method following PG. The third is the oncological safety in PG.

In the Western countries, TG is more often performed for proximal ECG. The following concerns may be the reason why PG is considered to inferior to TG for proximal gastric cancer. The first concern is whether the quality of life after PG is better than after TG, regarding loss of body weight and suffering malnutrition. The second is postoperative anastomosis-related complications including, anastomotic leakage and stenosis. The third is the occurrence of severe reflux esophagitis after PG. Therefore, many surgeons in the Western countries have chosen to perform TG even for upper-third EGC. To improve these concerns, various reconstruction procedures following PG have been developing, especially in Japan. Until now, three reconstruction methods, including double-tract reconstruction (DT), jejunal interposition (JI), and esophagogastrostomy, have been popularly performed following PG in Japan. However, a 
standard reconstruction procedure following PG has not been established because each procedure has some disadvantages.

Esophagogastrostomy is the simplest reconstruction procedure than other procedures, DT and Jl. However, esophagogastrostomy have a high risk of reflux esophagitis and anastomotic stenosis. Therefore, several procedures for preventing reflux esophagitis in esophagogastrostomy have been reported. Okabe et al. reported the reconstruction method with an esophagogastrostomy using a knifeless linear stapler and hand suturing [20]. This procedure is similar to our method in that the use of linear stapler and the fixation of the esophagus onto the anterior wall of the remnant stomach. However, their procedure is end-to-side anastomosis by continuous hand suturing. Hand suturing of anastomosis is likely the cause of anastomotic stenosis. Yamashita et al. reported a new method of esophagogastrostomy, side overlap with fundoplication by Yamashita (SOFY) [21]. They performed side overlap esophagogastrostomy by linear stapler rotated counterclockwise on its axis, suturing the gastric wall to the left side of the esophagus. This method is also easily procedure like our method, but concerns about reflux still remain due to the patients' position. Kamikawa et al. described a novel esophagogastrostomy procedure with double-flap technique [22], and this procedure was applied to LPG [23-25]. Although the short-term outcomes regarding reflux prevention following these procedures have been reported to be satisfactory, these techniques are very complicated. So, these challenging techniques may prevent the widespread use of LPG for upper one-third of EGC.

As shown in the present study, our novel procedure is so simple and can be easily and safely performed even younger surgeons who are familiar with the laparoscopic standard technique. Characteristics of our novel reconstruction method are as follows: (1) reconstruction by a long and narrow gastric tube with the sufficient capacity; (2) making a pseudo-gastric angle by long gastric tube; (3) a pseudo-fundus by making gastric tube with widening of the proximal side like a cobra's head; (4) preserving the excretory function of residual stomach by avoidance of No.5 and No.6 node dissection around the pyloric ring; (5) the anastomosis by on-lay method with tight suturing between the esophageal muscularis fascia and the gastric tube flatten the esophagus; (6) fixing the esophagus to bilateral crus of diaphragm for the prevention of twisting and lifting of the esophageal stump. In this study, reflux esophagitis of grade $\mathrm{C}$ was observed in only three patients $(10 \%)$ because of these additional reflux prevention systems. Besides, we noted no other anastomosis-related complications during this study. These results suggest that our novel reconstruction method is a feasible procedure as the reconstruction following PG.

Several studies have concluded that long-term outcomes of open PG for proximal ECG were not shown to be different from those of open TG $[10,26,27]$. Oncological safety in LPG might have not become a major concern due to these previous results. Thus, there is little evidence of oncological safety of LPG. Ahn et al. reported that overall survival for proximal gastric cancer was similar when comparing LPG and LTG [28]. In our study, recurrence was observed in only 2 patients with advanced proximal gastric cancer. We have been expanding operative indication from early to advanced gastric cancer, recently. We consider that LPG may be an oncologically acceptable procedure for stage I and IIA at least. Large sample size of patients is necessary to confirm these considerations. 
The present study has some limitations. First, this was a retrospective and limited study at a single institution. Second, the nutritional status of patients was not examined in this study. Third, the comparison of outcomes did not include TG. Further examination and longer follow up of patients are needed.

\section{Conclusions}

In conclusion, LPG with long and narrow gastric tube reconstruction method can easily performed, and may be feasible for the treatment of gastric cancer in the upper third of the stomach because of safe technique for preventing anastomosis-related complications, the especially esophageal reflux.

\section{Abbreviations}

LPG

laparoscopic proximal gastrectomy

EGC

early gastric cancer

TG

total gastrectomy

CD

Clavien-Dindo classification

DT

double-tract reconstruction

$\mathrm{JI}$

jejunal interposition

SOFY

side overlap with fundoplication by Yamashita

\section{Declarations}

\section{Ethics approval and consent to participate}

This study was approved by the Ethical Committee of Oita University Faculty of Medicine (Approval No. 542), and all patients included in the study gave their written informed consent. The study was conducted in accordance to Helsinki declarations, Ethiopian National Research Ethics Guidelines, and Institutional regulations on research ethics.

\section{Consent for publication}

Not applicable.

\section{Availability of data and materials}


All data generated or analyzed during this study are included in this published article.

\section{Competing interests}

The authors declare that they have no competing interests.

\section{Funding}

This research did not receive any specific grant from funding agencies in the public, commercial, or notfor-profit sectors.

\section{Authors' contribution}

YU, KT, and NS proposed and designed the study. YU and ST wrote the draft. YU, TK, KS, SN, and HS collected and analyzed the data. All authors contributed to the design and interpretation of the study and to further drafts. TE, MI, and NS revised the manuscript. All authors read and approved the final manuscript.

\section{Acknowledgements}

Not applicable.

\section{References}

1. Deans C, Yeo MS, Soe MY, Shabbir A, Ti TK, So JB. Cancer of the gastric cardia is rising in incidence in an Asian population and is associated with adverse outcome. World J Surg. 2011 Mar;35(3):61724.

2. Kusano C, Gotoda T, Khor CJ, Katai H, Kato H, Taniguchi H, Shimoda T. Changing trends in the proportion of adenocarcinoma of the esophagogastric junction in a large tertiary referral center in Japan. J Gastroenterol Hepatol. 2008 Nov;23(11):1662-5.

3. Uyama I, Ogiwara H, Takahara T, Kikuchi K, lida S. Laparoscopic and minilaparotomy proximal gastrectomy and esophagogastrostomy: technique and case report. Surg Laparosc Endosc. 1995 Dec;5(6):487-91.

4. Inomata M, Shiroshita H, Uchida H, Bandoh T, Akira S, Yamaguchi S, Kurokawa Y, Seki Y, Eguchi S, Wada N, Takiguchi S, leiri S, Endo S, Iwazaki M, Sato Y, Tamaki Y, Kitamura K, Tabata M, Kanayama H, Mimata H, Hasegawa T, Takahashi H, Onishi K, Uemura T, Hashizume M, Matsumoto S, Kitano S, Watanabe M. Current status of endoscopic surgery in Japan: The 14th National Survey of Endoscopic Surgery by the Japan Society for Endoscopic Surgery. Asian J Endosc Surg. 2020; 13: 718.

5. Takiguchi N, Takahashi M, Ikeda M, Inagawa S, Ueda S, Nobuoka T, Ota M, Iwasaki Y, Uchida N, Kodera Y, Nakada K. Long-term quality-of-life comparison of total gastrectomy and proximal 
gastrectomy by postgastrectomy syndrome assessment scale (PGSAS-45): a nationwide multiinstitutional study. Gastric Cancer. 2015 Apr;18(2) 407-16.

6. Nishigori T, Okabe H, Tsunoda S, Shinohara H, Obama K, Hosogi H, Hisamori S, Miyazaki K, Nakayama T, Sakai Y. Superiority of laparoscopic proximal gastrectomy with hand-sewn esophagogastrostomy over total gastrectomy in improving postoperative body weight loss and quality of life. Surg Endosc. 2017 Sep;31(9):3664-3672.

7. Japanese Gastric Cancer Association. Japanese gastric cancer treatment guidelines 2018 (5th edition). Gastric Cancer. 2021 Jan;24(1):1-21.

8. An JY, Youn HG, Choi MG, Noh JH, Sohn TS, Kim S. The difficult choice between total and proximal gastrectomy in proximal early gastric cancer. Am J Surg. 2008; 196(4):587-591

9. Ahn SH, Lee JH, do Park J, Kim HH. Comparative study of clinical outcomes between laparoscopyassisted proximal gastrectomy (LAPG) and laparoscopy-assisted total gastrectomy (LATG) for proximal gastric cancer. Gastric Cancer. 2013; 16(3):282-289.

10. Jung DH, Ahn SH, Park DJ, Kim HH. Proximal Gastrectomy for Gastric Cancer. J Gastric Cancer. 2015 Jun;15(2):77-86.

11. Kitano S, Adachi Y, Shiraishi N, Suematsu T, Bando T. Laparoscopic-assisted proximal gastrectomy for early gastric carcinomas. Surg Today 1999; 29:389-391.

12. Sakuramoto S, Yamashita K, Kikuchi S, Futawatari N, Katada N, Moriya H, et al. Clinical experience of laparoscopy-assisted proximal gastrectomy with Toupet-like partial fundoplication in early gastric cancer for preventing reflux esophagitis. J Am Coll Surg 2009; 209:344-351.

13. Yasuda A, Yasuda T, Imamoto H, Kato H, Nishiki K, Iwama M, et al. A newly modified esophagogastrostomy with a reliable angle of His by placing a gastric tube in the lower mediastinum in laparoscopy-assisted proximal gastrectomy. Gastric Cancer. 2015 Oct;18(4):850-8.

14. Kinoshita T, Gotohda N, Kato Y, Takahashi S, Konishi M, Kinoshita T. Laparoscopic proximal gastrectomy with jejunal interposition for gastric cancer in the proximal third of the stomach: a retrospective comparison with open surgery. Surg Endosc 2013; 27:146-153.

15. Nomura E, Lee SW, Kawai M, Yamazaki M, Nabeshima K, Nakamura K, et al. Functional outcomes by reconstruction technique following laparoscopic proximal gastrectomy for gastric cancer: double tract versus jejunal interposition. World J Surg Oncol 2014; 12:20.

16. Adachi Y, Katsuta T, Aramaki M, Morimoto A, Shiraishi N, Kitano S. Proximal gastrectomy and gastric tube reconstruction for early cancer of the gastric cardia. Dig Surg. 1999; 16(6):468-70.

17. Ueda Y, Shiraishi N, Toujigamori M, Shiroshita H, Etoh T, Inomata M. Laparoscopic Proximal Gastrectomy with Gastric Tube Reconstruction. JSLS. Jul-Sep 2016; 20(3): e2016.00046.

18. Clavien PA, Barkun J, de Oliveira ML, Vauthey JN, Dindo D, Schulick RD, de Santibañes E, Pekolj J, Slankamenac K, Bassi C, Graf R, Vonlanthen R, Padbury R, Cameron JL, Makuuchi M. The ClavienDindo classification of surgical complications: five-year experience. Ann Surg. 2010, 250:187-196.

19. Armstrong D, Bennett JR, Blum AL, Dent J, Dombal FTD, Galmiche JP, et al. The endoscopic assessment of esophagitis: a progress report on observer agreement. Gastroenterology 1996; 
111:85-92.

20. Okabe H, Obama K, Tanaka E, Tsunoda S, Akagami M, Sakai Y. Laparoscopic proximal gastrectomy with a hand-sewn esophago-gastric anastomosis using a knifeless endoscopic linear stapler. Gastric Cancer 2013;16:268-274.

21. Yamashita Y, Yamamoto A, Tamamori Y, Yoshii M, Nishiguchi Y. Side overlap esophagogastrostomy to prevent reflux after proximal gastrectomy. Gastric Cancer. 2017 Jul;20(4):728-735.

22. Kamikawa Y, Kobayashi T, Ueyama $S$ et al (2001) A new antireflux procedure in esophagogastrostomy after proximal gastrectomy. Shokakigeka 24:1053-1060 (Japanese).

23. Muraoka A, Kobayashi M, Kokudo Y. Laparoscopy-Assisted Proximal Gastrectomy with the Hinged Double Flap Method. World J Surg. 2016 Oct;40(10):2419-24.

24. Kuroda S, Nishizaki M, Kikuchi S, Noma K, Tanabe S, Kagawa S, Shirakawa Y, Fujiwara T. DoubleFlap Technique as an Antireflux Procedure in Esophagogastrostomy after Proximal Gastrectomy. J Am Coll Surg. 2016 Aug;223(2):e7-e13.

25. Hayami M, Hiki N, Nunobe S, Mine S, Ohashi M, Kumagai K, Ida S, Watanabe M, Sano T, Yamaguchi T. Clinical Outcomes and Evaluation of Laparoscopic Proximal Gastrectomy with Double-Flap Technique for Early Gastric Cancer in the Upper Third of the Stomach. Ann Surg Oncol. 2017 Jun;24(6):1635-1642.

26. Wen $L$, Chen XZ, Wu B, Chen XL, Wang L, Yang K, et al. Total vs. proximal gastrectomy for proximal gastric cancer: a systematic review and meta-analysis. Hepatogastroenterology. 2012; 59:633-640.

27. Yoo CH, Sohn BH, Han WK, Pae WK. Long-term results of proximal and total gastrectomy for adenocarcinoma of the upper third of the stomach. Cancer Res Treat 2004; 36:50-55.

28. Ahn SH, Lee JH, Park do J, Kim HH. Comparative study of clinical outcomes between laparoscopyassisted proximal gastrectomy (LAPG) and laparoscopy-assisted total gastrectomy (LATG) for proximal gastric cancer. Gastric Cancer 2013; 16:282-289.

\section{Figures}




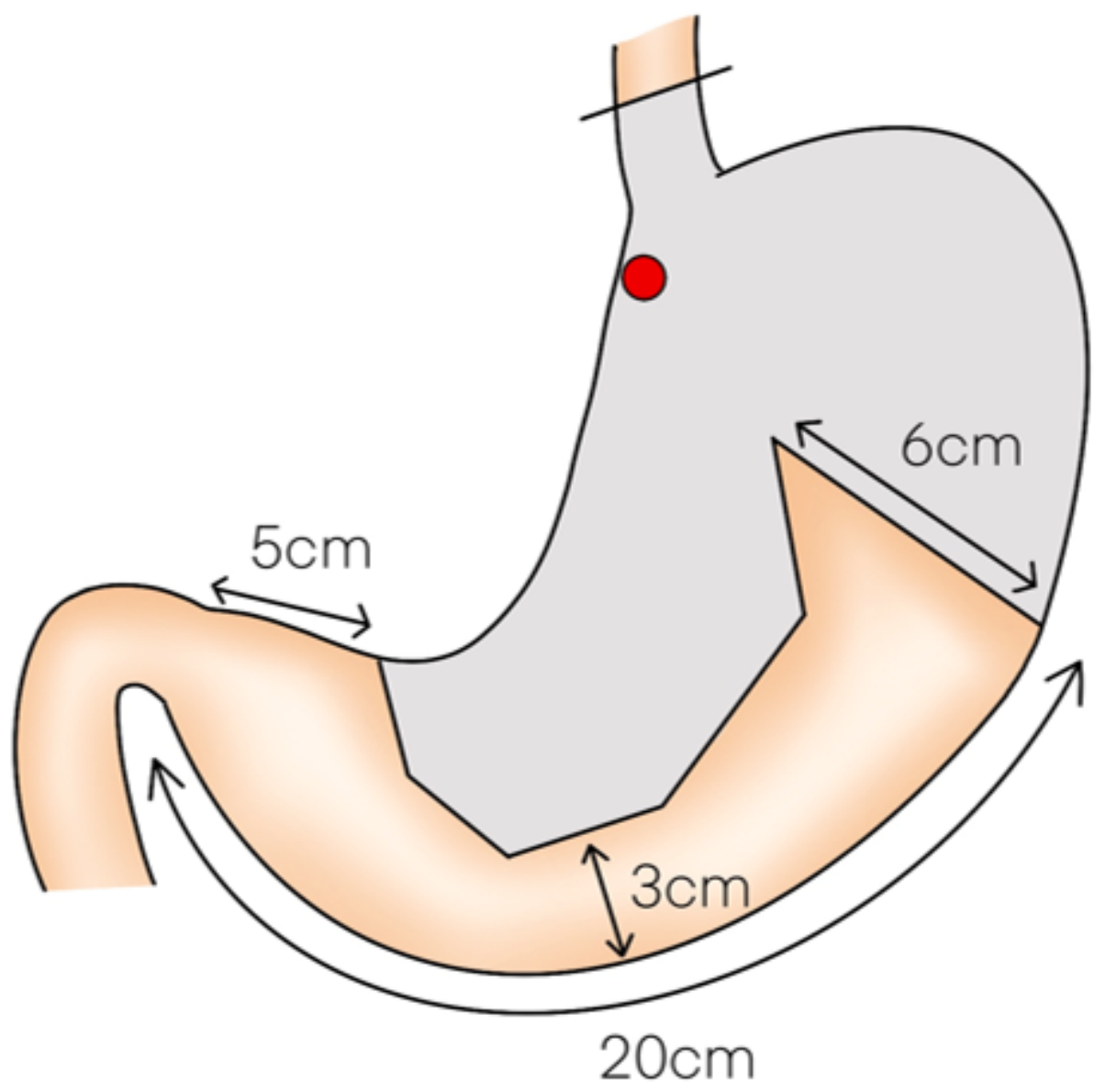

Figure 1

Schematic of the formation of a long and narrow gastric tube like a cobra's head.
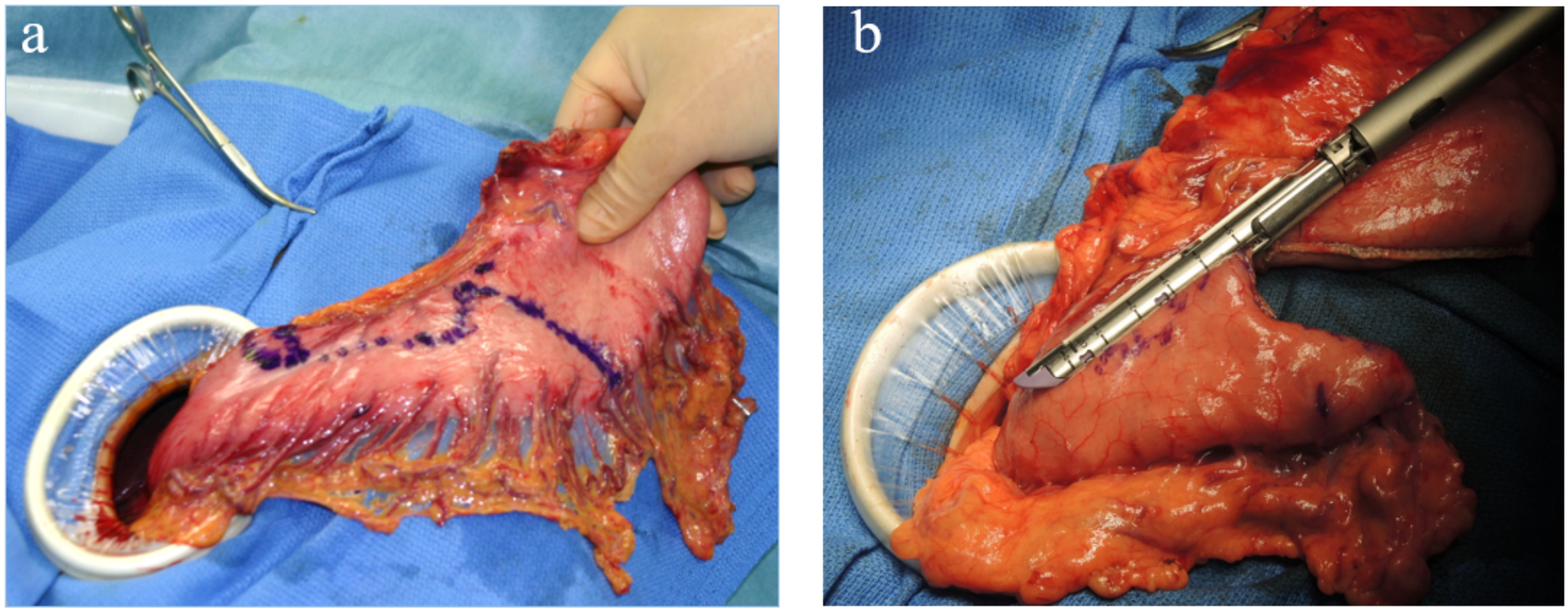

Figure 2 
A long and narrow gastric tube like a cobra's head is created using by linear stapler.

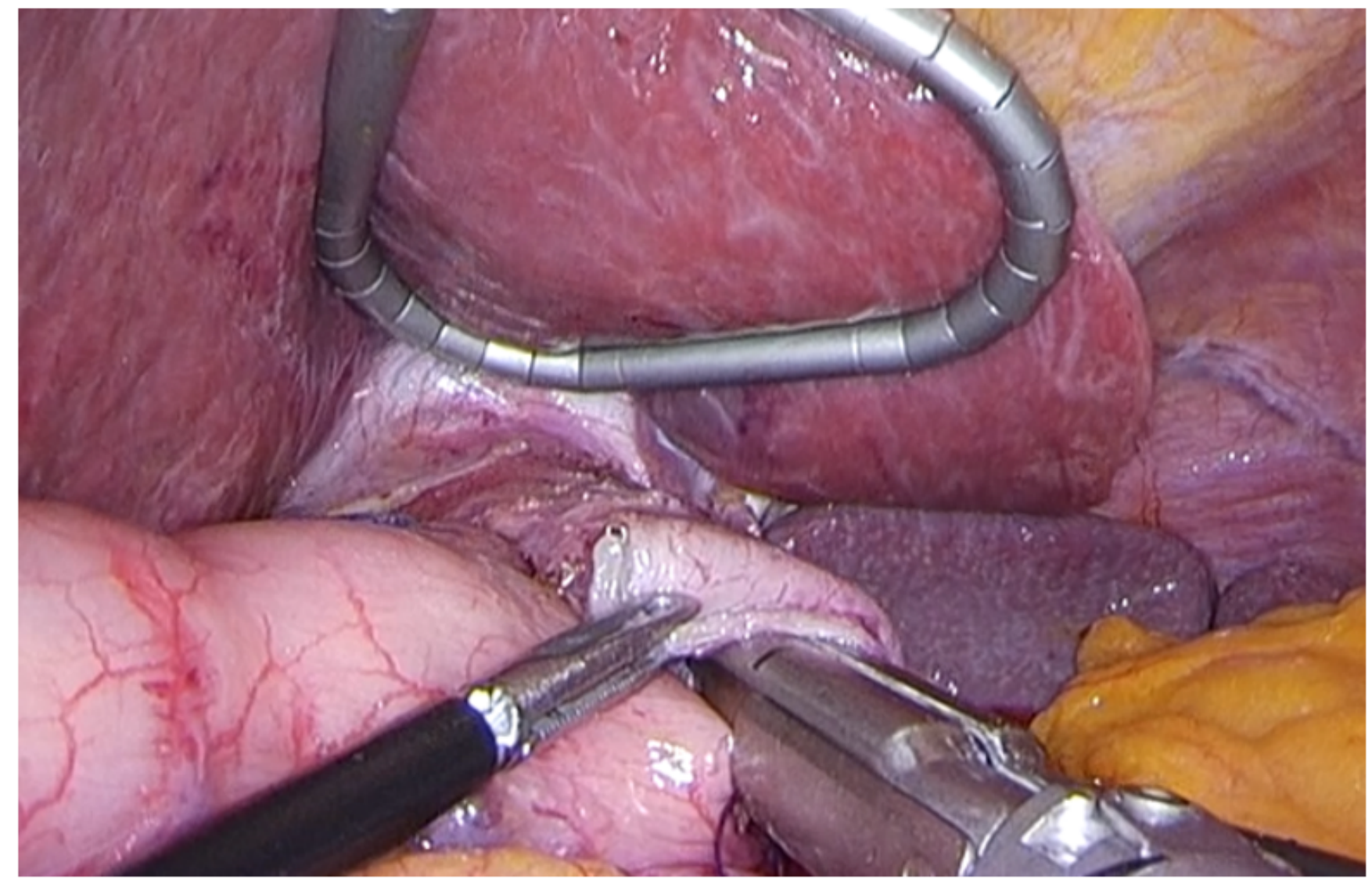

Figure 3

Direct anastomosis with overlap method between the posterior wall of the esophagus and anterior wall of the gastric tube using a $45-\mathrm{mm}$ linear stapler. 


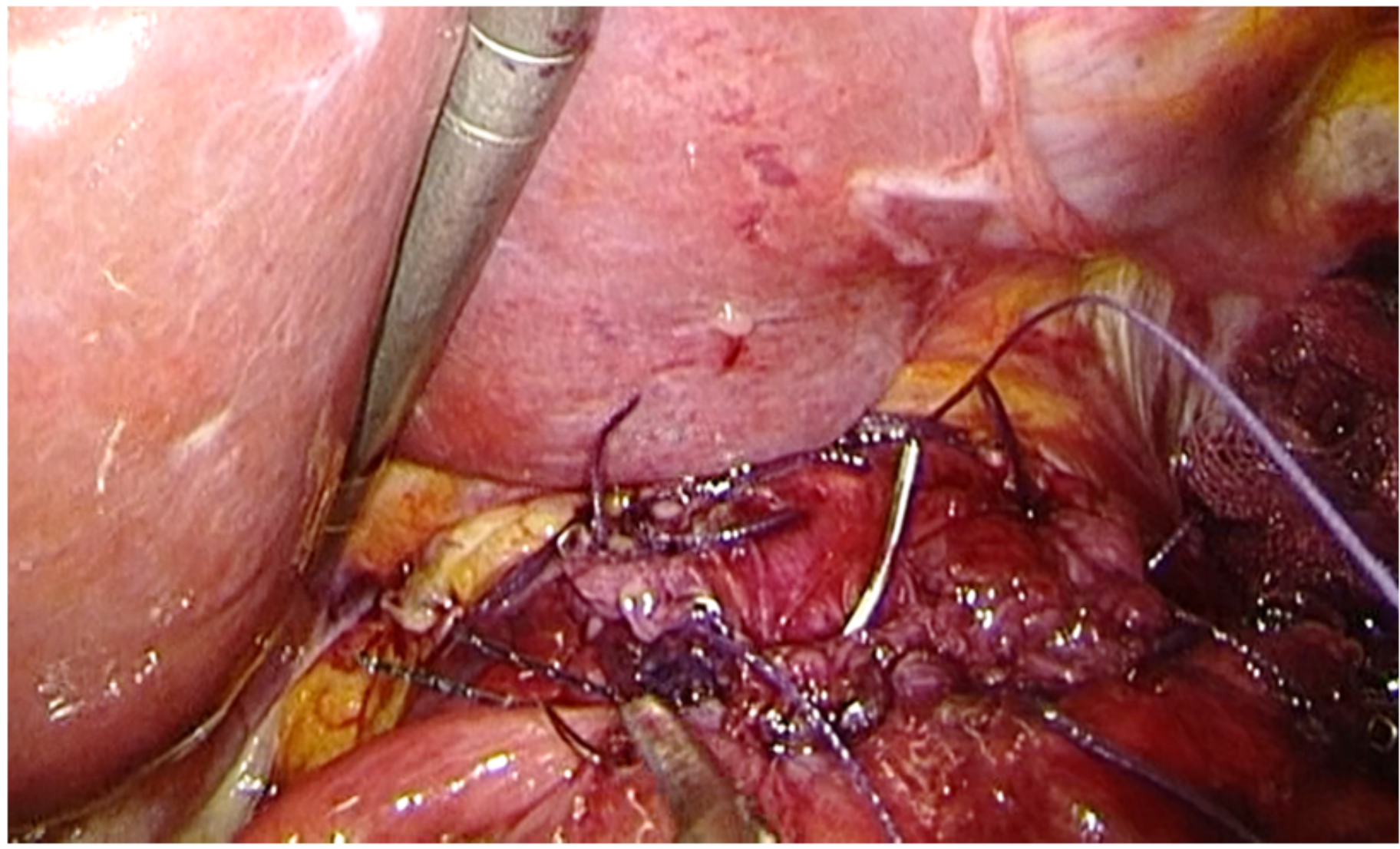

Figure 4

The right ends of the esophageal wall are fixed to the gastric wall. 


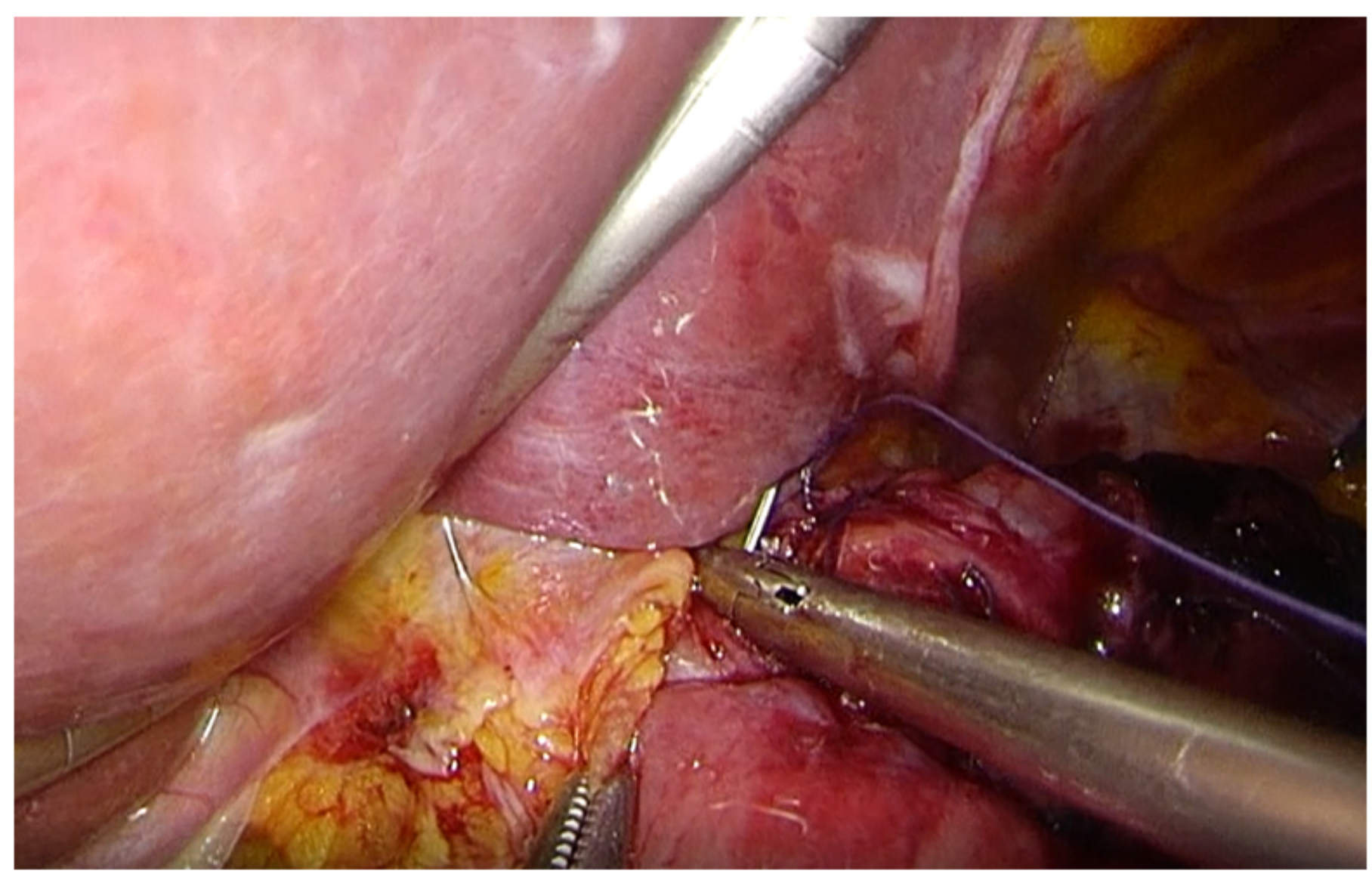

Figure 5

The suture fixation between right crus of diaphragm and esophagus wall. 


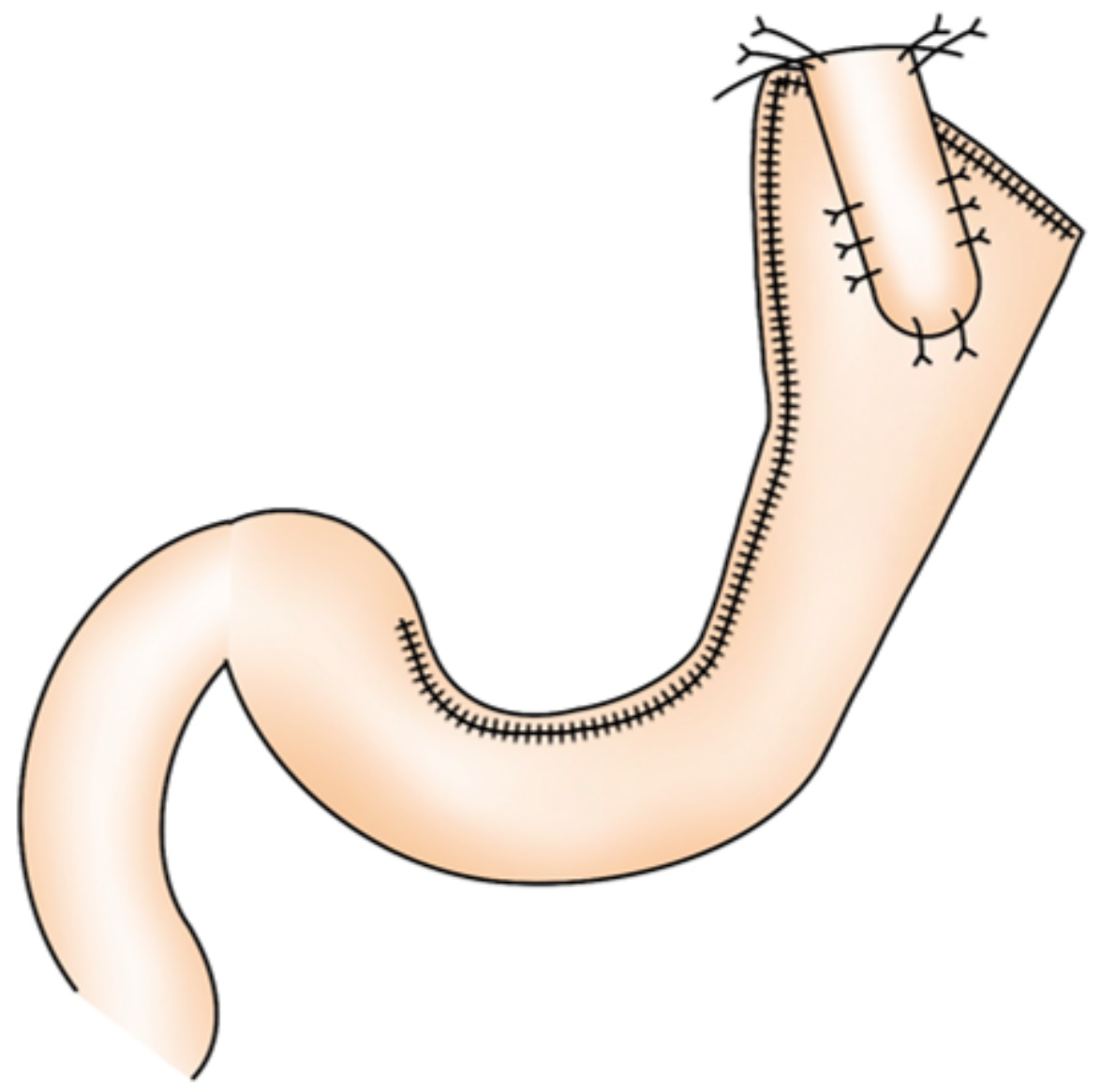

Figure 6

Schematic of the completion of a novel reconstruction method. 